\title{
SIX MONTHS OUTCOME OF LOCO-REGIONAL TREATMENT OF HEPATOCELLULAR CARCINOMA AT ADVANCED LIVER CENTER, ZAGAZIG UNIVERSITY
}

\author{
Mohamed Hassan Ibrahima ${ }^{a}$, Hussein Mohammed Hussein ${ }^{a}$, Sameh Saber Bayoumi ${ }^{b}$, Heba Sayed \\ Abdel Hamid ${ }^{\text {. }}$. \\ ${ }^{a}$ Internal Medicine Department, Zagazig University, Egypt. ${ }^{\mathrm{b}}$ Radiology Department, Zagazig \\ University, Egypt.
}

\author{
Received: 1 October 2018 \\ Accepted: 18 December 2018 \\ Corresponding author \\ Heba Sayed Abdel Hamid \\ dr.hebazrka@yahoo.com
}

\begin{abstract}
Background: Hepatocellular carcinoma (HCC) represents one of the few cancers for which loco-regional treatments are recognised as being able to cure and/or prolong survival and are included in international guidelines. The treatment choice in patients with $\mathrm{HCC}$ is therefore driven not only by tumour staging, as in the great majority of cancers, but also by careful evaluation of liver function and physical status. We aimed to evaluate the outcome of locoregional treatment of hepatocellular carcinoma at Zagazig University.

Methods: From June 2017 to December 2017, 30 patients with HCC who Patients' candidate for loco-regional treatment according to BCLC were included that followed prospectively in this study.

Results: There was a significant improvement after treatment as regard albumin,total, direct bilirubin, INR, AFP and focal size , and a significant successful of treatment by $70 \%$ of the cases. Positive HCV is a significant risk factor for treatment failure.

Conclusions: Loco-regional treatments have a significant role in patients with HCC at all stages. Literature data support the use of image-guided ablation, primarily RFA, as the first-line treatment in patients with very early and early-stage HCC.
\end{abstract}

Keywords: Hepatocellular carcinoma, Loco-regional treatments

\section{INTRODUCTION}

H epatocellular carcinoma (HCC) has an increasing incidence worldwide. It is the second cause of cancer-related death worldwide. [1] In Egypt, HCC is the second most common cancer in men and the $6^{\text {th }}$ most common cancer in women. ${ }^{[2]}$ Multiple factors are responsible for the initiation and progression of $\mathrm{HCC}$ include virus-induced, alcohol-induced, fungi-induced hepatocarcinogenesis, obesity and type II diabetes. ${ }^{[3]}$ All cirrhotic patients and those with chronic infection with hepatitis $\mathrm{B}$ or $\mathrm{C}$ virus are at higher risk for developing $\mathrm{HCC}$ and should be enrolled In screening using ultrasound and serum a-fetoprotein (AFP). [4] Individuals with focal lesions in ultrasound examination require further examination with triphasic computed tomography (CT), magnetic resonance imaging (MRI), and/or liver biopsy to confirm the diagnosis of HCC. ${ }^{[5]}$ The treatment choice in patients with HCC is driven not only by tumour staging, as in the great majority of cancers, but also by careful evaluation of liver function and physical status. Another specific feature of HCC is that it is the only tumour that can be cured by organ transplantation, with the aim of treating both cancer and underlying liver disease. These characteristics configure a complex scenario and prompt the need for close cooperation among interventional radiologist, surgeons, hepatologists, and anesthesiologists. [6] The Barcelona Clinic Liver Cancer (BCLC) algorithm classifies HCC into five stages based 
on the extent of the disease, child-pugh score and performance status PS. ${ }^{[7]}$ Very early stage (stage 0 ) in which the patient with PS is zero and the child score A with single focal lesion less than 2 $\mathrm{cm}$. Early stage (stage A) in which the patient with PS is zero and the child score A or B, with single lesion or less than 3 nodules less than 3 $\mathrm{cm}$. Intermediate stage (stage B) in which the patient with PS is zero and the child score A or B with multinodular focal lesion. Advanced stage (stage C) in which the patient with PS is 1 or 2 and the child score is A or B with vascular invasion or extrahepatic spread of the tumor. Terminal stage (D) in which the patient with PS is 4 and the child score $\mathrm{C}$ and with tumor of any size and number. ${ }^{[8]}$ Loco-regional treatment include ablation (microwave ablation and radiofrequency ablation), which are considered as curative treatment in very early and early stage and transarterial chemoembolization (TACE) which considered as palliative treatment. [9] This study was done to evaluate the outcome of loco- regional treatment of hepatocellular carcinoma at Zagazig University.

\section{MATERIALS AND METHODS}

The present study was performed in the period from June 2017 to December 2017 in outpatient clinic of advanced liver center of Zagazig University Hospitals. Subjects included in this study 30 patients who followed prospectively.

Inclusion Criteria included patients who candidate for loco-regional treatment according to BCLC and patients with intermediate-stage HCC.

After excluded patients with advanced stage of HCC with multiple focal lesions, vascular invasion and extrahapatic spread, Child-Pugh $\mathrm{C}$ and performance state 4 and other malignancy informed consent was taking, Clinical examination was performed .

Routine laboratory investigation were performed according to clinical pathology department of Zagazig university hospitals protocols and included $\mathrm{CBC}$, kidney function tests, liver function tests, bleeding profile and virology.
Alpha-Fetoprotein (AFP) and Radiological investigations including abdominal ultrasonography and Triphasic abdominal CT for (Number, site and size of the focal lesion/s).

Three types of treatment applied: Radiofrequency ablation (RFA), Microwave ablation (MWA). Transarterial chemoembolization (TACE).

\section{Follow up}

Outpatient follow up visits was arranged in 1,3 and 6 months for evaluation. Blood samples are taken for assessment treatment status. Liver function: serum albumin, AST, ALT and AFP \& triphasic CT are estimated at 3 and 6 months.

\section{STATISTICAL ANALYSIS}

All data were collected, tabulated and statistically analyzed using SPSS 20.0 for windows (SPSS Inc., Chicago, IL, USA) \& MedCalc 13 for windows (MedCalc Software bvba, Ostend, Belgium). Quantitative data were expressed as the mean \pm SD \& median (range), and qualitative data were expressed as absolute frequencies (number) \& relative frequencies (percentage). Continuous variables were checked for normality by using Shapiro-Wilk test. Paired t-test was used to compare between two dependent groups of normally distributed variables while Wilcoxon signed ranks test was used for non-normally distributed variables. Repeated measures ANOVA test was used to compare between more than two dependent groups of normally distributed variables while Friedman's test ranks test was used for nonnormally distributed variables. Paired categorical variables were compared using McNemar's test. Stuart-Maxwell test (different generalization of McNemar test) was used for testing marginal homogeneity in a square table with more than two rows/columns. P-value $<0.05$ was considered statistically significant $(\mathrm{S})$, p-value < 0.001 was considered highly statistically significant (HS), and p-value $\geq 0.05$ was considered statistically insignificant (NS).

\section{RESULTS}

The demographic features of the two groups are described (Table 1). 
Table 1 patients' parameters according to type of treatment.

\begin{tabular}{|c|c|c|c|}
\hline Variable & TACE & MWA & RFA \\
\cline { 2 - 4 } & $(\mathrm{N}=13)$ & $(\mathrm{N}=16)$ & $(\mathrm{N}=2)$ \\
\hline $\begin{array}{c}\text { Age }(\text { years }) \\
\text { Mean } \pm \text { SD }\end{array}$ & $60.46 \pm 9.31$ & $62.33 \pm 8.17$ & $63.50 \pm 0.71$ \\
\hline Sex Male & $8(61.5 \%)$ & $9(56.3 \%)$ & $0(0 \%)$ \\
\hline Female & $5(38.5 \%)$ & $7(43.7 \%)$ & $2(100 \%)$ \\
\hline $\begin{array}{c}\text { Platelets }\left(10^{3} / \mu \mathrm{L}\right) \\
\text { Mean } \pm \text { SD }\end{array}$ & $109.62 \pm 50.46$ & $108.67 \pm 53.73$ & $136.00 \pm 69.29$ \\
\hline $\begin{array}{c}\text { AFP }(\mathrm{ng} / \mathrm{ml}) \\
\text { Mean } \pm \text { SD }\end{array}$ & $943.25 \pm 1583.39$ & $18.81 \pm 10.356$ & $28.20 \pm 37.91$ \\
\hline $\begin{array}{c}\text { Serum albumin }(\mathrm{g} / \mathrm{dl}) \\
\text { Mean } \pm \text { SD }\end{array}$ & $3.25 \pm 0.81$ & $3.61 \pm 0.59$ & $3.4 \pm 0.99$ \\
\hline $\begin{array}{c}\text { AST }(\mathrm{U} / \mathrm{L}) \\
\text { Mean } \pm \text { SD }\end{array}$ & $60.23 \pm 47.56$ & $38.33 \pm 32.78$ & $39.00 \pm 0$ \\
\hline $\begin{array}{c}\text { ALT }(\mathrm{U} / \mathrm{L}) \\
\text { Mean } \pm \text { SD }\end{array}$ & $45.69 \pm 34.11$ & $33.13 \pm 22.45$ & $44.5 \pm 9.19$ \\
\hline $\begin{array}{c}\text { Total bilirubin }(\mathrm{mg} / \mathrm{dl}) \\
\text { Mean } \pm \text { SD }\end{array}$ & $1.077 \pm 0.398$ & $1.10 \pm 0.37$ & $0.85 \pm 0.71$ \\
\hline $\begin{array}{c}\text { Direct bilirubin }(\mathrm{mg} / \mathrm{dl}) \\
\text { Mean } \pm \text { SD }\end{array}$ & $0.515 \pm 0.391$ & $0.427 \pm 0.296$ & $0.25 \pm 0.71$ \\
\hline $\begin{array}{c}\text { INR } \\
\text { Mean } \pm \text { SD }\end{array}$ & $1.21 \pm 0.28$ & $1.25 \pm 0.28$ & $1.25 \pm 0.354$ \\
\hline $\begin{array}{c}\text { Focal size (cm) } \\
\text { Mean } \pm \text { SD }\end{array}$ & $46.23 \pm 22.63$ & $29.73 \pm 13.12$ & $32.29 \pm 12.73$ \\
\hline \begin{tabular}{c} 
Recurrence \\
\hline
\end{tabular} & $4(30.8 \%)$ & $2(13.3 \%)$ & $1(50 \%)$ \\
\hline
\end{tabular}

Table 2 Outcome of treatment of the studied patients

\begin{tabular}{|c|c|c|c|c|c|}
\hline & \multirow{2}{*}{$\mathbf{R}$} & \multicolumn{2}{|c|}{$\begin{array}{c}\text { 95\% Confidence Interval } \\
\text { of the Difference }\end{array}$} & \multirow{2}{*}{$\begin{array}{c}\text { Sig. (2- } \\
\text { tailed) }\end{array}$} \\
\cline { 3 - 5 } & & Lower & Upper & & \\
\hline AST & .331 & -51.92389 & 15.19056 & -1.119 & .272 \\
\hline ALT & .273 & -1.17698 & 22.51031 & 1.842 & .056 \\
\hline Albumin & .044 & -.98435 & -.28232 & -3.690 & $\mathbf{. 0 0 1}$ \\
\hline Total Bilirubin & .757 & .21790 & .42210 & 6.410 & $\mathbf{. 0 0 0}$ \\
\hline Direct Bilirubin & .717 & .07846 & .26154 & 3.798 & $\mathbf{. 0 0 1}$ \\
\hline INR & .850 & .03007 & .14993 & 3.071 & $\mathbf{. 0 0 5}$ \\
\hline AFP & .935 & -1173.02666 & -11.57534 & -2.086 & $\mathbf{. 0 4 6}$ \\
\hline Focal Size & .836 & 13.11618 & 35.31549 & 3.298 & $\mathbf{. 0 0 2}$ \\
\hline Treatment Success & $70 \%$ & ----- & ------ & 15.703 & $\mathbf{. 0 0 0}$ \\
\hline
\end{tabular}

\section{DISCUSSION}

Hepatocellular carcinoma (HCC) represents one of the few cancers for which locoregional treatments are recognised as being able to cure and/or prolong survival and are January 2019 Volume 25 Issue 1 included in international guidelines. This is due to the unique nature of $\mathrm{HCC}$, in most cases occurring in patients with underlying virus- or alcohol-related cirrhosis. ${ }^{[8]}$

The treatment choice in patients with $\mathrm{HCC}$ is therefore driven not only by tumour staging, 
as in the great majority of cancers, but also by careful evaluation of liver function and physical status. Another specific feature of HCC is that it is the only tumour that can be cured by organ transplantation, with the aim of treating both cancer and underlying liver disease. These characteristics configure a complex scenario and prompt the need for close cooperation among interventional oncologists, surgeons, hepatologists, and anaesthesiologists. ${ }^{[9]}$

Decision making for treatment of $\mathrm{HCC}$ is supported by guidelines endorsed by different societies worldwide: European Association for the Study of the Liver (EASL) and the European Organization for Research and Treatment of Cancer (EORTC), American Association for the Study of Liver Diseases (AASLD), Asian Pacific Association for the Study of Liver (APASL), Korean Liver Cancer Study Group and the Japan Society of Hepatology. the Differences in recommendations among guidelines mirror differences in cancer epidemiology, technique availability, and expertise in various countries. [10]

The Barcelona Clinic Liver Cancer (BCLC) classification has emerged during recent years as the standard classification that is used for clinical management of patients with HCC. This classification links stage stratification with a recommended treatment strategy, and defines the standard of care for each tumor stage. ${ }^{[11]}$

Among the 30 patients included in this study, 16 patients $(53.3 \%)$ were males and 14 patients $(46.7 \%)$ were females with a ratio of [1.6: 1] with mean age $61.60 \pm 4.39$ years.

In our study there was $13.3 \%$ of the total number of patients were smoker, there was also two diabetic patients and one hypertensive among the studied patients.

This results disagree with the finding of Yao et al. ${ }^{[12]}$ who documented that among HCC patients the male percentage was $70 \%$ with mean age 45 years.

There also were 3 patients presenting with mild lower limb edema, 5 patients with flappy tremors and two (7\%) patients with ascites. Among the studied patients there were 53\% patients positive for $\mathrm{HCV}$ and $10 \%$ were positive $\mathrm{HBV}$

Our findings were that $23(77 \%)$ patients were Child-Pugh A and 7 (23\%) patients were Child-Pugh B with PS zero and mean MELD 8.5 .

In a study by Khalil et al. ${ }^{[13]}$ reported that their fifty patients were classified according to Child Pugh score into 15 patients with Child A, 20 patients with Child B and lastly 15 patients with Child $\mathrm{C}$ unlike our results. Hepatitis C infection was positive in their 50 patients but combined HBV\& $\mathrm{HCV}$ infection was in 8 patients.

In a study by Shah et al. ${ }^{[15]}$, they reported a similar findings that they found the median age was 61 years (range, 17-84 years), and 65\% of the patients were male of their study population. But unlike our findings the most common underlying liver diseases were hepatitis B (58\%) and hepatitis C viral infection were positive in $19 \%$ of the patients.

However, they found more than one half of the patients (54\%) who were diagnosed with HCC were asymptomatic at evaluation. Most patients had Child-Pugh class A (87\%) cirrhosis by clinical and laboratory evaluation. No patient with disease that was classified as Child-Pugh class $\mathrm{C}$ and this was in agreement with our results.

In our study we found single focal legion was the highest percentage finding by $50 \%$, and the right lobe was the most place where the focal legion found with mean focal size 45.55 $\mathrm{mm}$, regarding abdominal US.

Regarding triphasic CT; the single focal legion was also the highest percentage finding $53.4 \%$, and segments 2,3 and 8 were the most places for the legions. This findings was in line with Marin et al. ${ }^{[17]}$ finding.

Khalil et al. ${ }^{[13]}$ documented that Mass size less than or equal to $3 \mathrm{~cm}$ was found in 14 patients. 36 patients had mass size more than $3 \mathrm{~cm} .24$ patients were with single masses and 26 patients with multiple masses. Regarding 
site of masses, 31 patients were with right lobe masses, and 10 with left lobe masses.

Mansy et al. ${ }^{[14]}$ also reported a similar results as the documented that focal size less than or equal to $3 \mathrm{~cm}$ was found in 22 patients. In all, 28 patients had focal size more than 3 cm. 35 patients were with single masses and 15 patients with multiple masses. Regarding the site of masses, 31 patients were with right lobe masses, and 10 with left lobe masses.

In a study by Chen et al. ${ }^{[16]}$ on 220 sequential patients with $\mathrm{HCC}$, they reported that their age ranged 11 to 84 years $90.9 \%$ of the patients were males. Among the patients $9.1 \%$ had focal size $<2 \mathrm{~cm}, 28.2 \%$ of the patients had focal size $2-5 \mathrm{~cm}$ and $62.7 \%$ of the patients had focal size $>5$, these finding was similar to ours. However, unlike our results they reported that $25 \%$ of the patients had ascites and $100 \%$ of the patients were positive $\mathrm{HCV}$

In our study, there were $16(53.3 \%)$ treated with Microwave ablation their mean age was 62.33 years included 9 males, $13(43.3 \%)$ patients treated with transarterial chemoembolization their mean age was 60.46 years included 8 males, (43.3\%) and 2 (6.7\%) patients treated with Radio Frequency Ablation and they were males with mean age was 63.5 years

Khalil et al. ${ }^{[13]}$ observed that in radio frequency group there were 10 patients. One patient was under 50 years, 8 patients were between 50 and 60 years and one patient above 60 years. 9 patients were males and 1 patient was female. Ten patients treated with TransHepatic Chemo- Embolization (TACE group). Five patients were between 50 and 60 years and another five patients above 60 years. Nine patients were males and one was female. Also Mansy et al. ${ }^{[14]}$ reported a similar finding

A role for loco-regional therapy can be further justified by the fact that patients with HCC usually die of liver failure as a result of local growth and resultant liver tissue destruction, but not as a result of extra-hepatic metastatic disease. Loco-regional therapies are now commonly used to treat unresectable liver cancer ${ }^{[18]}$

Khalil et al. ${ }^{[13]}$ documented that treatment with Radio Frequency Ablation, local ablation is safe and effective as palliative therapy for patients who cannot undergo resection. TransArterial Chemo-Embolization should be used for multi-nodular (>3 nodules) HCC. TACE considered for patients with nonsurgical hepatocellular carcinoma that are also ineligible for percutaneous ablation, provided there is no extra-hepatic tumorspread.

The frequency of recurrence in our study was 7 patients $(23.3 \%)$ after 6 months. We found that the positive $\mathrm{HCV}$ patients was the most likely risk for recurrence.

Khalil et al. ${ }^{[13]}$ reported that recurrence was in 3 patients (12\%), one patient developed recurrence after 6 months, 2 patients within two years. Also Shah et al. reported that recurrence incidence was $8 \%, 52.5 \%$ and $71 \%$ at 6 months, one year and 2 years respectively.

Khalil et al. ${ }^{[13]}$ reported that tumor size and active cirrhosis, Satellites and vascular invasion were the main factors affecting recurrence rate in HCC patients, the same was Mansy et al. ${ }^{[14]}$ However, Mansy et al. ${ }^{[14]}$ suggested that the high incidence of $\mathrm{HCV}$ infection in Egypt, which proved to have a direct relationship with occurrence of HCC.

We recommend a surveillance program to provide a data-supported approach to the diagnosis, staging, treatment, and management of HCC.

\section{CONCLUSION}

Loco-regional treatments have a significant role in patients with $\mathrm{HCC}$ at all stages. Literature data support the use of image-guided ablation, primarily RFA, as the first-line treatment in patients with very early and earlystage HCC.

TACE is the treatment of choice, with improved survival, for patients with intermediate stage HCC. Similar overall survival rates have been obtained with conventional Lipiodol TACE and DEB-TACE, the latter being better tolerated. An economic, 
cost-effectiveness approach would be helpful in assessing the respective role of these intraarterial approaches.

\section{REFERENCES}

[1] World Health Organization. Mortality database. WHO statistical information system. 2008 Available at: <http://www.who. int/whosis.

[2] GLOBOCAN 2008 database (version 1.2). 2008 Available online: <http://globocan.iarc.fr.

[3] Rinku Dutta, Ram I. Mahato: Department of Pharmaceutical Sciences, University of Nebraska Medical Center, Omaha, NE 68198, United States 2017.

[4] Bruix J and Sherman M. Management of hepatocellular carcinoma. Hepatology, 2005;42(5):1208e36.

[5] Lau WY and Lai ECH. Hepatocellular carcinoma: current management and recent advances. Hepatobiliary Pancreat Dis Int. 2008;7:237-57.

[6] Bruix J and Sherman M: Practice Guidelines Committee, American Association for the Study of Liver Diseases. Management of hepatocellular carcinoma. Hepatology, 2010.

[7] Llovet JM, Burroughs A and Bruix J. Hepatocellular carcinoma. Lancet. 2003; 362: 1907-17.

[8] EASL-EORTC clinical practice guidelines: management of hepatocellular carcinoma. J Hepatol. 2012; 56(4):908e43.

[9] Crocetti L., I. Bargellini, R. Cioni. Division of Interventional Radiology, Department of Diagnostic and Interventional Radiology and Nuclear Medicine,Cisanello University Hospital, Pisa, Italy 2017.

[10] Kokudo N, Hasegawa K, Akahane M, et al. Evidence-based clinical practice guidelines for hepatocellular carcinoma: the Japan Society of
Hepatology 2013 update (3rd JSH-HCC Guidelines). Hepatol Res 2015;45(2).

[11] Bruix J, Reig M, Sherman M. Evidence-based diagnosis, staging, and treatment of patients with hepatocellular carcinoma. Gastroenterology 2016;150(4):835-53.

[12] Yao FY, Hirose R, LaBerge JM, et al. A prospective study on downstaging of hepatocellular carcinoma prior to liver transplantation. Liver Transpl. 2005; 11 (12): 1505-1514.

[13] Khalil H, Yehia M, El-shewy A, Mansy W. Different Modalities In Management of Hepatocellular Carcinoma. ZUMJ 2011; 17 (1): 62-76.

[14] Mansy W, Mohammed M, El-Wahsh M, Khalil H, Amer K. Treatment options for HCC: a combined hospital experience. Egyptian $\mathbf{J}$ Surgery 2014; 33: 245-251.

[15] Shah SA, Cleary SP, Wei AC, Yang I, Taylor BR, Hemming AW, et al. Recurrence after liver resection for hepatocellular carcinoma: risk factors, treatment, and outcomes. Surgery 2007; 141: 330-339.

[16] Chen ZH, Hong YF, Chen X, Chen J, Lin Q, Lin J, et al. Comparison of five staging systems in predicting the survival rate of patients with hepatocellular carcinoma undergoing transarterial chemoembolization therapy. Oncol Lett. 2018; 15 (1): 855-862.

[17] Marin D, Cappabianca S, Serra N, Sica A, Lassandro F, et al. CT Appearance of Hepatocellular Carcinoma after Locoregional Treatments: A Comprehensive Review. Gastroenterol Res Pract. 2015; 2015: 670965.

[18] Okuda K. Hepatocellular carcinoma. J Hepatol 2004; 32:225-237

How to cite this article: Ibrahim MH, Hussein HM, Bayoumi SS, Abdel Hamid HS. Six months outcome of loco-regional treatment of hepatocellular carcinoma at advanced liver center, Zagazig University. ZUMJ 2019; 25 (1): 16-21. 